\title{
Micro-computed Tomography Analysis of the Effect of Immersion Time on Volumetric Stability of Different Endodontic Materials
}

\author{
Fernanda Ferrari Esteves Torres ${ }^{a}$, Juliane Maria Guerreiro-Tanomaru ${ }^{a}$, Roberta Bosso-Martelo ${ }^{b}$, \\ Camila Galletti Espir ${ }^{a}$, Jáder Camilo Pinto ${ }^{a}$, Mário Tanomaru-Filho ${ }^{a}$ * (D) \\ ${ }^{a}$ Universidade Estadual Paulista (UNESP), Faculdade de Odontologia, Departamento de Odontologia \\ Restauradora, Araraquara, SP, Brasil. \\ ${ }^{b}$ Universidade Federal da Bahia (UFBA), Faculdade de Odontologia, Departamento de Odontologia, \\ Salvador, BA, Brasil
}

Received: May 8, 2020; Revised: June 11, 2020; Accepted: July 14, 2020

\begin{abstract}
Dental materials should be stable over time. This study investigated volumetric change of the root canal sealers AH Plus, Fill Canal, and Sealapex; and the root-end filling materials Biodentine, IRM, and MTA after different periods of immersion in distilled water. Resin models were manufactured with cavities $3 \mathrm{~mm}$ deep. The cavities were filled with the materials and scanned by microcomputed tomography after setting, and after 7 and 30 days immersed in distilled water. Percentages of volumetric changes after 7 and 30 days of immersion were compared by t-test. ANOVA/Tukey tests were used to compare endodontic materials (5\% significance level). All root canal sealers had an increase in their volumetric change after 30 days. Among root-end filling materials, only IRM showed difference between the periods. Biodentine showed more volumetric changes than MTA, but both materials kept their volume from 7 to 30 days. In conclusion, the immersion period of endodontic materials may affect their stability.
\end{abstract}

Keywords: Dental materials, endodontics, physical properties, $x$-ray microtomography.

\section{Introduction}

Dental materials should be investigated regarding their properties $^{1,2}$. Standardized tests are defined by the American Dental Association (ADA) ${ }^{3}$ and International Organization for Standardization (ISO $)^{4}$ for solubility and dimensional change analyses of root canal sealers ${ }^{5}$.

Endodontic materials may not present high solubility, which could allow leakage, leading to an unsuccessful treatment ${ }^{6}$. The dimensional stability is also an important physical property, since shrinkage may lead to leakage, compromising the sealing ability ${ }^{7}$. Although ISO 6876 has protocols for assessing the solubility and dimensional change of materials, there are no standards for analyzing the volumetric changes of endodontic materials ${ }^{8}$.

Microcomputed tomography (micro-CT) has been used as a complementary tool to evaluate the solubility and dimensional stability of endodontic materials by the volumetric change analysis after immersion of the materials in a fluid ${ }^{8-10}$. Micro-CT analysis allows an accurate assessment ${ }^{11}$, and its use in high resolution allows analysis of microstructural characteristics $^{12}$. Moreover, due to its nondestructive characteristic, it is possible to analyze the same specimen over time ${ }^{8,10}$. In order to evaluate the volumetric change of materials by using micro-CT, cavities have been filled with the materials, decreasing the contact with the fluid to allow a methodology similar to the clinic condition ${ }^{6,8-10}$.

*e-mail: tanomaru@uol.com.br
Aiming to evaluate the materials behavior, the solubility of endodontic cements has been evaluated for longer periods. A previous study ${ }^{13}$ showed that root canal sealers based on calcium silicate or salicylate resin showed high solubility during 6 months of evaluation. This assessment over time shows that some materials could not be stable ${ }^{14}$, which may compromise the sealing ${ }^{7}$. Most studies have evaluated volumetric stability of endodontic materials after 7 days of immersion $^{6,8-10}$. Although some studies have been evaluated materials after 30 days $^{8,10}$, no comparison was performed between volumetric changes in the two periods of immersion in distilled water. This comparison between periods using micro-CT can demonstrate the volumetric stability of repair materials or endodontic sealers based on different compositions after different periods of immersion in distilled water, reflecting its behavior in relation to volumetric stability over time.

The aim of this study was to compare by using micro-CT the volumetric stability of different endodontic cements and root canal sealers after 7 and 30 days of immersion in distilled water. The null hypothesis was that there is no effect of immersion time in distilled water on the volumetric change of the materials.

\section{Experimental}

\subsection{Volumetric change evaluation}

The evaluation of the volumetric change of the materials was performed based on a previous study ${ }^{8}$. Cavities in acrylic resin measuring $3 \mathrm{~mm}$ deep were manufactured 
using metal molds and filled with AH Plus, Fill Canal, Sealapex, Biodentine, IRM and MTA ( $n=12$ per group). The materials evaluated with their respective manufacturer, composition and proportion used are described in Table 1. The cavities were radiographed using a digital X-ray (Kodak RVG 6100 Digital Radiography System, Marne-la-Vallée, France) for a previous analysis of their complete filling. Samples that did not have adequate filling were discarded. The samples were kept in an oven at $37^{\circ} \mathrm{C}$ and $95 \%$ humidity for 2 days to the root-end filling materials and 7 days when using the root canal sealers. The scanning procedure was performed by micro-CT SkyScan 1176 (Bruker, Kontich, Belgium) after setting and after 7 and 30 days of immersion of the specimens in distilled water. The following scanning parameters were used: $50 \mathrm{kV}$ power, $500 \mu \mathrm{A}$ energy, aluminum filter of $0.5 \mathrm{~mm}, 18 \mu \mathrm{m}$ voxel size, and an evolution cycle of $360^{\circ}$. A schematic figure of the volumetric change assessment is illustrated in Figure 1. The images were reconstructed using NRecon software (V1.6.4,7; Bruker) and superimposed with geometric alignment using the Data Viewer software (V1.5.1, Bruker). Quantitative analyses were performed using CTAn software (V1.14.4, Bruker). For this propose, a region of interest (ROI) was defined maintaining the materials inside the cavities and excluding the resin mold. Then, the histogram was defined by the automatic thresholding plug-in available on CTAn software. Regarding the grayscale indexes, the value of 255 was standardized on the top region of the graph, while its bottom region showed

Table 1. Endodontic materials, their manufacturers, composition, and proportion used

\begin{tabular}{|c|c|c|c|}
\hline Material & Manufacturer & Composition & Proportion \\
\hline AH Plus & $\begin{array}{l}\text { DentsplyDeTrey. } \\
\text { Konstanz, Germany }\end{array}$ & $\begin{array}{l}\text { Paste A: bisphenol epoxy resin-A, bisphenol epoxy } \\
\text { resin-F, calcium tungstate, zirconium oxide, silica, } \\
\text { iron oxide pigments. } \\
\text { Paste B: dibenzyldiamine, aminodiamantana, } \\
\text { tricyclodecane-diamine, calcium tungstate, zirconium } \\
\text { oxide, silica, silicone oil. }\end{array}$ & $1 \mathrm{~g}:$ \\
\hline Fill Canal & $\begin{array}{l}\text { Technew Com. Ind. Ltda. } \\
\text { Rio de Janeiro, RJ, Brazil }\end{array}$ & $\begin{array}{l}\text { Powder: hydrogen resin, bismuth subcarbonate, } \\
\text { barium sulfate and sodium borate } \\
\text { Liquid: eugenol and sweet almond oil. }\end{array}$ & $\begin{array}{c}1 \mathrm{~g}: \\
0,20 \mathrm{~mL}\end{array}$ \\
\hline Sealapex & $\begin{array}{l}\text { SybronEndo - Sybron Dental } \\
\text { Specialties. } \\
\text { Glendona, CA, USA }\end{array}$ & $\begin{array}{l}\text { Base paste: sulphonamide resin, N-ethyl toluene, } \\
\text { silicon dioxide, zinc oxide, calcium oxide; } \\
\text { Catalyst paste: isobutyl salicylate resin, silicon } \\
\text { dioxide, bismuth trioxide, titanium dioxide, pigments }\end{array}$ & $1 \mathrm{~g}:$ \\
\hline Biodentine & $\begin{array}{l}\text { Septodont. } \\
\text { Saint-Maur-des-Fossés, France }\end{array}$ & $\begin{array}{l}\text { Powder: tricalcium silicate, calcium carbonate, } \\
\text { zirconium oxide, dicalcium silicate, calcium oxide, } \\
\text { iron oxide } \\
\text { Liquid: aqueous solution of a hydrosoluble polymer } \\
\text { with calcium chloride }\end{array}$ & $\begin{array}{l}1 \mathrm{~g}: \\
6 \text { drops }\end{array}$ \\
\hline IRM & $\begin{array}{c}\text { Dentsply. } \\
\text { Caulk Milford,DE }\end{array}$ & $\begin{array}{l}\text { Powder: zinc oxide, poly methyl methacrylate } \\
\text { Liquid: eugenol, acetic acid }\end{array}$ & $\begin{array}{c}1 \mathrm{~g}: \\
0,2 \mathrm{~mL}\end{array}$ \\
\hline MTA & $\begin{array}{l}\text { Angelus. } \\
\text { Londrina, PR, Brazil }\end{array}$ & $\begin{array}{l}\text { Powder: tricalcium silicate, dicalcium silicate, } \\
\text { tricalcium aluminate, calcium oxide, bismuth oxide } \\
\text { Liquid: distilled water }\end{array}$ & $\begin{array}{c}1 \mathrm{~g}: \\
0,33 \mathrm{~mL}\end{array}$ \\
\hline
\end{tabular}

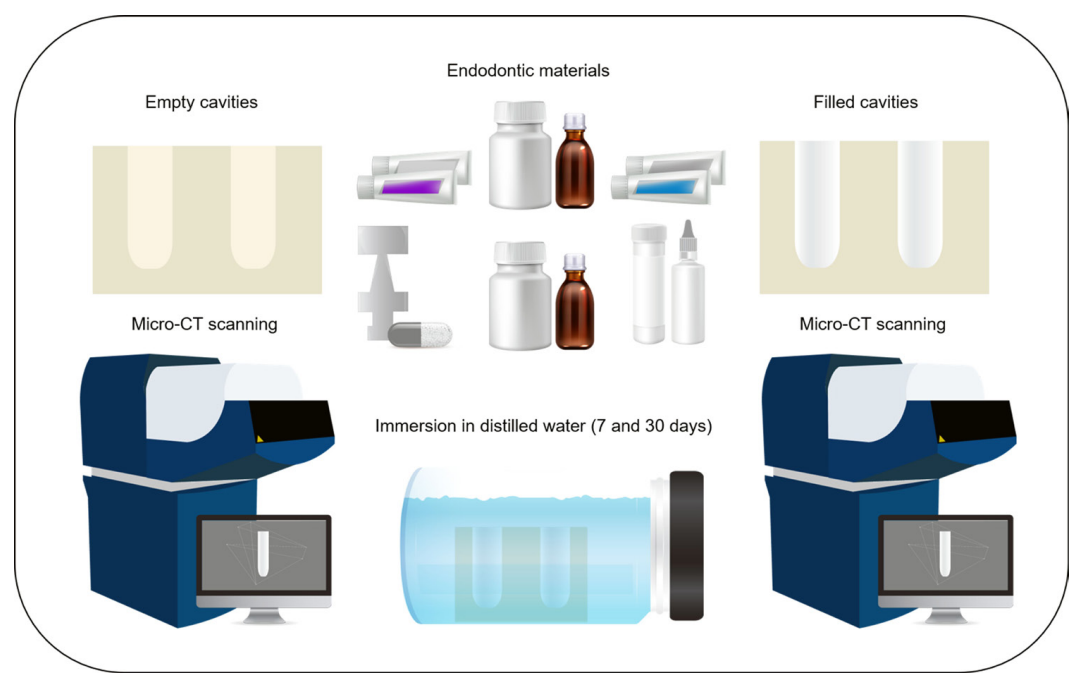

Figure 1 - Schematic figure representing the volumetric change assessment. Transparent acrylic resin-based models with cavities measuring $3 \mathrm{~mm}$ deep were filled with the different materials, and scanned in micro-CT after setting. The samples were scanned again after 7 and 30 days of immersion in distilled water. 
values that ranged from 80 to 110 , according to the density of the endodontic material. The total volume of the cavities filled with each material was quantified and the volumetric change was considered the difference between the baseline volume values and the values of the experimental periods of 7 and 30 days. To obtain the percentage of volumetric change of the materials, the following formula was used: [Percentage of volumetric change $=(($ material volume after immersion / initial material volume) -1) *100].

\subsection{Statistical analysis}

All data were analysed with the GraphPad Prism 7.00 (GraphPad Software, La Jolla, CA, USA) statistical software package. Data were submitted to normality test, and One-way ANOVA/Tukey tests were used for statistical differences among the endodontic materials. T-testing was used for comparison of the changes at the time points. The level of significance was set at $5 \%$.

\section{Results and Discussion}

Several studies follow the ANSI/ADA specification to perform investigations in the endodontic research ${ }^{15}$. Although the ISO/ADA standards indicate materials solubility evaluation after 24 hours of immersion, longer periods have been used. These longer periods of assessment are important since some materials could not maintain their properties over time $\mathrm{e}^{13,14}$.

Although ISO/ADA standards are recommended for assessing root canal sealers, there is no specification for root-end filling materials. In addition, the solubility test may not be appropriate, as samples and contact with liquid do not reflect a clinical situation ${ }^{14}$. It can also be seen that dehydration performed before evaluating the final mass for evaporation of the free water content interferes in the analysis of hydraulic calcium silicates materials which presenting high weight loss using these methods ${ }^{16}$. These limitations led to the use of new methodologies such as micro-CT to complement conventional tests by obtaining relevant data ${ }^{17}$. Therefore, the current study used this non-destructive tri-dimensional approach $^{9}$, which allowed to evaluate the behavior of different endodontic materials after 7 and 30 days of immersion. In addition, the materials were evaluated inside the cavities, reducing contact with the fluid.

Between the scanning periods, interaction of endodontic materials with the aqueous medium may occur, mainly for hydrophilic materials ${ }^{7}$. Therefore, an effect of the immersion time on the volumetric stability was observed for all the root canal sealers evaluated besides the root-end filling material IRM $(p<0.05)$, rejecting our null hypothesis. The results of the current study regarding the evaluation of the root canal sealers and the root-end filling materials are showed in Table 2 and Table 3, respectively. Representative models of volume gain and volume loss after immersion are represented in Figure 2.

AH Plus had a volume increase after 7 days of immersion and a slight volume loss after 30 days $(p<0.05)$. On the other hand, Sealapex had volume loss in both periods, with the highest values after 30 days $(p<0.05)$. The results observed after 7 days for AH Plus occurred probably because of its low solubility associate with its expansion ${ }^{5}$. Our findings corroborates Silva et al. ${ }^{18}$, which evaluated the solubility of AH Plus after 1, 7, 14 and 28 days of immersion. The authors observed an increase in the solubility of this sealer over time, from $0.41 \%$ at 7 days to $0.71 \%$ of mass loss after 28 days. Although an effect of the immersion time has been observed, the values were below $1 \%$, showing the stability of $\mathrm{AH}$ Plus, in agreement with previous studies ${ }^{13,14}$. This stability could be justified by the strong cross-links in the resinous polymers of AH Plus ${ }^{5}$. Regarding Sealapex, the solubility and shrinkage previously observed for this sealer ${ }^{5}$ could contribute for the result of volume loss. Sealapex has a complex and inhomogeneous setting reaction, with the presence of

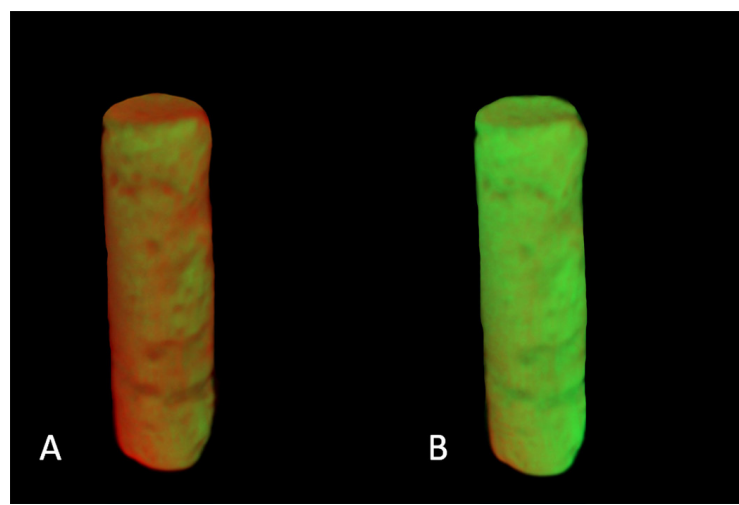

Figure 2 - 3D models created in CTVox software illustrating the volumetric change before (green) and after (red) immersion in distilled water. A: representative image of volume gain after immersion. B: representative image of volume loss after immersion.

Table 2. Volumetric change values (\%) after 7 and 30 days (mean and standard deviation) observed in root canal sealers

\begin{tabular}{cccc}
\hline Volumetric Change $(\%)$ & AH Plus & Fill Canal & Sealapex \\
\hline 7 days & $0.65(0.26)^{\mathrm{A}, \mathrm{b}}$ & $0.89(0.19)^{\mathrm{A}, \mathrm{c}}$ & $-0.48(0.18)^{\mathrm{A}, \mathrm{a}}$ \\
\hline 30 days & $-0.32(0.11)^{\mathrm{B}, \mathrm{b}}$ & $-0.42(0.11)^{\mathrm{B}, \mathrm{c}}$ & $-1.18(0.49)^{\mathrm{B}, \mathrm{a}}$ \\
\hline
\end{tabular}

${ }^{\mathrm{AB}}$ Different capital letter in the same column indicate statistically significant difference between the time points $(p<0.05)$. abc Different lower case letters on the same row indicate statistically significant difference among the sealers $(p<0.05)$. Negative values indicate volume loss.

Table 3. Volumetric change values (\%) after 7 and 30 days (mean and standard deviation) observed in endodontic cements

\begin{tabular}{cccc}
\hline Volumetric Change (\%) & Biodentine & IRM & MTA \\
\hline 7 days & $-2.19(0.76)^{\mathrm{A}, \mathrm{a}}$ & $0.77(0.18)^{\mathrm{A}, \mathrm{b}}$ & $-0.51(0.23)^{\mathrm{A}, \mathrm{c}}$ \\
\hline 30 days & $-2.07(0.66)^{\mathrm{A}, \mathrm{a}}$ & $-1.46(0.47)^{\mathrm{B}, \mathrm{b}}$ & $-0.49(0.20)^{\mathrm{A}, \mathrm{c}}$ \\
\hline
\end{tabular}

${ }^{\mathrm{AB}}$ Different capital letter in the same column indicate statistically significant difference between the time points $(p<0.05)$. ${ }^{\text {abc }}$ Different lower case letters on the same row indicate statistically significant difference among the cements $(p<0.05)$. Negative values indicate volume loss. 
porosities that can increase the solubilization of this sealer ${ }^{19}$. The presence of bismuth oxide as a radiopacifying agent can also contribute to its integrity reduction ${ }^{20}$.

Some characteristics of zinc oxide and eugenol-based materials and their interaction with a fluid medium such as the properties of wash-out, sorption and fluid uptake were few investigated ${ }^{21}$. However, greater solubility ${ }^{22}$ and infiltration ${ }^{23}$ have been observed for these materials when in comparison with resin-based materials. Fill Canal and IRM are zinc oxide and eugenol-based materials. Both materials had a volume gain after 7 days, while after 30 days a volume loss was observed for them $(p<0.05)$. The initial volumetric increase for IRM and Fill Canal could be related to the interaction of the aqueous medium with the polymers in the composition of these materials, such as poly methyl methacrylate and hydrogen resin, respectively. After 30 days, a leaching effect of eugenol could lead to disintegration and volume loss ${ }^{24}$

Calcium silicate-based repair cements are widely used in endodontics for vital pulp therapy, internal/external resorption, perforation repair, and root-end filling ${ }^{25}$. The calcium silicate component lead to an increase of bioactivity and improvement in the mechanical properties of cements ${ }^{26}$. Biodentine and MTA are calcium silicate-based cements that present bioactive potential, influencing the repair of adjacent tissues ${ }^{27}$. According to our results, both materials kept their volume loss from 7 to 30 days $(p>0.05)$. A previous study $^{28}$ investigated the solubility of MTA since its mixture until 672 hours, and observed values above the 3\% weight lost considered acceptable by the ISO standard. However, the authors also stated a high initial solubility followed by a constant decrease over time for $\mathrm{MTA}^{28}$. This statement corroborates another long-term investigation regarding MTA solubility ${ }^{29}$, which demonstrated that MTA is soluble over time but with a decreasing rate. This previous study also allege that MTA is mainly composed by an insoluble matrix of silica that maintains its integrity even in contact with water, besides the capacity of MTA to promote a high $\mathrm{pH}$ that was maintained in the aqueous environment over time ${ }^{29}$. Our study did not consider only the mass loss of MTA, but its complete volumetric behavior, which is in agreement with previous findings showing the volumetric stability of $\mathrm{MTA}^{10}$. This result suggests that water uptake may compensate the solubility of MTA, since its hydration process promotes an increase in volume ${ }^{28}$.

Biodentine showed greater volume loss than $\operatorname{MTA}(p<0.05)$. The solubility of Biodentine has been reported ${ }^{10,17,30-32}$. However, there is no long-term investigation regarding Biodentine solubility. Moreover, for calcium silicate-based cements, the solubilization of their components may have biological relevance ${ }^{14}$, favoring ion release and bioactive potential with formation of apatite ${ }^{16}$. Biodentine also has expansion $^{17}$ and fluid uptake ${ }^{30}$, which could compensate its weight loss. Furthermore, when characterizing and investigating the hydration of Biodentine and MTAAngelus, Camilleri et al. ${ }^{33}$ showed that Biodentine resulted in a material with enhanced chemical properties, while the clinker of MTA Angelus was incompletely sintered leading to a variability in its mineralogy, besides less amount of tricalcium silicate. Moreover, MTA presents some disadvantages as its consistency and long time required for setting ${ }^{34}$. Therefore, Biodentine presents some advantages and although this material showed a higher volume loss than MTA in both periods evaluated, MTA and Biodentine had volumetric stability between 7 and 30 days.

Based on the results of the current study, the volumetric stability of the materials depends on their basic composition. Regarding the root canal sealers, although AH Plus and Fill Canal were affected by the immersion time, their changes were below $1 \%$. Sealapex had higher volume loss than the other sealers, with greater values after 30 days. However, its solubilization could promotes calcium and hydroxyl ions release, which may aid in the bioactivity of this sealer ${ }^{16}$. Among the root-end filling materials, MTA had the greatest volumetric stability.

\section{Conclusions}

In conclusion, the immersion period can influence the volumetric change of materials and their stability from 7 to 30 days. The dimensional behavior of endodontic materials should be evaluated at different times, since changes may affect the clinical success. New protocols using micro-CT to evaluate dental materials must be established to identify volumetric stability over time.

\section{Acknowledgments}

The authors would like to thank Renato Luiz Carvalho for his assistance with the illustrations. This study was financed in part by the Coordenação de Aperfeiçoamento de Pessoal de Nível Superior - Brazil (CAPES) - Finance Code 001. This work was also supported by Fundação de Amparo à Pesquisa do Estado de São Paulo - FAPESP (2016/00321-0, 2017/19049-0 and 2018/19665-6).

\section{References}

1. Santos E Jr, Nascimento KDP, Camargo SS Jr. Relation between in-vitro wear and nanomechanical properties of commercial light-cured dental composites coated with surface sealants. Mater Res. 2013;16:1148-55.

2. Benevides AP, Campos AR, Vieira LC, Perez CR, Cesar DV. Reduced graphene oxide-zinc oxide flower-like composite for glass-ionomer materials reinforcement. Mater Res. 2020;23:e20190580.

3. American National Standards. American Dental Association. Specification no. 57 for endodontic sealing materials. Chicago, IL: American National Standards/American Dental Association; 2000 .

4. International Organization for Standardization. ISO 6876: dental root canal sealing materials. Geneva, Switzerland: ISO; 2012.

5. Viapiana R, Flumignan DL, Guerreiro-Tanomaru JM, Camilleri J, Tanomaru-Filho M. Physicochemical and mechanical properties of zirconium oxide and niobium oxide modified Portland cement-based experimental endodontic sealers. Int Endod J. 2014;47:437-48

6. Cavenago BC, Pereira TC, Duarte MA, Ordinola-Zapata R, Marciano MA, Bramante CM, et al. Influence of powder-towater ratio on radiopacity, setting time, $\mathrm{pH}$, calcium ion release and a micro-CT volumetric solubility of white mineral trioxide aggregate. Int Endod J. 2014;47:120-6. 
7. Orstavik D, Nordahl I, Tibballs JE. Dimensional change following setting of root canal sealer materials. Dent Mater. 2001;17:512-9.

8. Tanomaru-Filho M, Torres FFE, Chavez-Andrade GM, de Almeida M, Navarro LG, Steier L, et al. Physicochemical Properties and volumetric change of silicone/bioactive glass and calcium silicate-based endodontic sealers. J Endod. 2017;43:2097-101.

9. Silva EJ, Perez R, Valentim RM, Belladonna FG, De-Deus GA, Lima IC, et al. Dissolution, dislocation and dimensional changes of endodontic sealers after a solubility challenge: a micro-CT approach. Int Endod J. 2017;50:407-14.

10. Torres FFE, Jacobs R, EzEldeen M, Guerreiro-Tanomaru JM, Santos BC, Lucas-Oliveira E, et al. Micro-computed tomography high resolution evaluation of dimensional and morphological changes of 3 root-end filling materials in simulated physiological conditions. J Mater Sci Mater Med. 2020;31:14.

11. Pforringer D, Harrasser N, Muhlhofer H, Kiokekli M, Stemberger A, van Griensven M, et al. Osteoinduction and -conduction through absorbable bone substitute materials based on calcium sulfate: in vivo biological behavior in a rabbit model. J Mater Sci Mater Med. 2018;29:17.

12. Cengiz IF, Oliveira JM, Reis RL. Micro-computed tomography characterization of tissue engineering scaffolds: effects of pixel size and rotation step. J Mater Sci Mater Med. 2017;28:129.

13. Urban K, Neuhaus J, Donnermeyer D, Schafer E, Dammaschke T. Solubility and $\mathrm{pH}$ value of 3 different root canal sealers: a long-term investigation. J Endod. 2018;44:1736-40.

14. Elyassi Y, Moinzadeh AT, Kleverlaan CJ. Characterization of leachates from 6 root canal sealers. J Endod. 2019;45:623-7.

15. Matheus TCU, Lopes HP, Albuquerque DS, Elias CN, Carmo AMR, Otuboa J, et al. The fracture evaluation of NiTi SMA endodontics files. Mater Res. 2007;10:395-8.

16. Gandolfi MG, Siboni F, Botero T, Bossu M, Riccitiello F, Prati C. Calcium silicate and calcium hydroxide materials for pulp capping: biointeractivity, porosity, solubility and bioactivity of current formulations. J Appl Biomater Funct Mater. 2015;13:4360 .

17. Torres FFE, Bosso-Martelo R, Espir CG, Cirelli JA, GuerreiroTanomaru JM, Tanomaru-Filho M. Evaluation of physicochemical properties of root-end filling materials using conventional and Micro-CT tests. J Appl Oral Sci. 2017;25:374-80.

18. Silva EJ, Accorsi-Mendonca T, Pedrosa AC, Granjeiro JM, Zaia AA. Long-Term Cytotoxicity, $\mathrm{pH}$ and Dissolution Rate of AH Plus and MTA Fillapex. Braz Dent J. 2016;27:419-23.

19. Borges RP, Sousa-Neto MD, Versiani MA, Rached-Junior FA, De-Deus G, Miranda CE, et al. Changes in the surface of four calcium silicate-containing endodontic materials and an epoxy resin-based sealer after a solubility test. Int Endod J. 2012;45:419-28.

20. Coomaraswamy KS, Lumley PJ, Hofmann MP. Effect of bismuth oxide radioopacifier content on the material properties of an endodontic Portland cement-based (MTA-like) system. J Endod. 2007;33:295-8.

21. Grech L, Mallia B, Camilleri J. Investigation of the physical properties of tricalcium silicate cement-based root-end filling materials. Dent Mater. 2013;29:e20-8.

22. Carvalho-Junior JR, Guimaraes LF, Correr-Sobrinho L, Pecora JD, Sousa-Neto MD. Evaluation of solubility, disintegration, and dimensional alterations of a glass ionomer root canal sealer. Braz Dent J. 2003;14:114-8.

23. De Almeida WA, Leonardo MR, Tanomaru M Fo, Silva LA. Evaluation of apical sealing of three endodontic sealers. Int Endod J. 2000;33:25-7.

24. Wilson AD, Batchelor RF. Zinc oxide-eugenol cements: II. Study of erosion and disintegration. J Dent Res. 1970;49:593-8.

25. Abedi-Amin A, Luzi A, Giovarruscio M, Paolone G, Darvizeh A, Agullo VV, et al. Innovative root-end filling materials based on calcium-silicates and calcium-phosphates. J Mater Sci Mater Med. 2017;28:31.

26. Morejón-Alonso L, Carrodeguas RG, Santos LA. Effects of silica addition on the chemical, mechanical and biological properties of a new a-tricalcium phosphate/tricalcium silicate cement. Mater Res. 2011;14:475-82.

27. Niu LN, Jiao K, Wang TD, Zhang W, Camilleri J, Bergeron $\mathrm{BE}$, et al. A review of the bioactivity of hydraulic calcium silicate cements. J Dent. 2014;42:517-33.

28. Bodanezi A, Carvalho N, Silva D, Bernardineli N, Bramante $\mathrm{CM}$, Garcia RB, et al. Immediate and delayed solubility of mineral trioxide aggregate and Portland cement. J Appl Oral Sci. 2008;16:127-31.

29. Fridland M, Rosado R. MTA solubility: a long term study. J Endod. 2005;31:376-9.

30. Torres FFE, Guerreiro-Tanomaru JM, Bosso-Martelo R, Chavez-Andrade GM, Tanomaru Filho M. Solubility, porosity and fluid uptake of calcium silicate-based cements. J Appl Oral Sci. 2018;26:e20170465.

31. Dawood AE, Manton DJ, Parashos P, Wong R, Palamara J, Stanton DP, et al. The physical properties and ion release of CPP-ACP-modified calcium silicate-based cements. Aust Dent J. 2015;60:434-44.

32. Quintana RM, Jardine AP, Grechi TR, Grazziotin-Soares R, Ardenghi DM, Scarparo RK, et al. Bone tissue reaction, setting time, solubility, and $\mathrm{pH}$ of root repair materials. Clin Oral Investig. 2019;23:1359-66.

33. Camilleri J, Sorrentino F, Damidot D. Investigation of the hydration and bioactivity of radiopacified tricalcium silicate cement, Biodentine and MTAAngelus. Dent Mater. 2013;29:58093.

34. Perard M, Le Clerc J, Watrin T, Meary F, Perez F, Tricot-Doleux $\mathrm{S}$, et al. Spheroid model study comparing the biocompatibility of biodentine and MTA. J Mater Sci Mater Med. 2013;24:152734. 